\title{
USING ADULT EDUCATION TO IMPROVE THE SUSTAINABILITY OF WATER RESOURCES IN THE PACIFIC NORTHWEST, USA
}

\author{
ROBERT L. MAHLER ${ }^{1} \&$ MICHAEL E. BARBER ${ }^{2}$ \\ ${ }^{1}$ Soil Science Division, University of Idaho, Moscow, ID, USA. \\ ${ }^{2}$ Department of Civil and Environmental Engineering, University of Utah, Salt Lake City, UT, USA.
}

\begin{abstract}
The purpose of this paper is to document actions taken by the public in the Pacific Northwest (PNW) to improve the sustainability of their water resources since 2002. A survey instrument was used to collect these data in 2002, 2007 and 2012. Mail-based surveys containing between 45 and 60 questions were sent to over 2,200 randomly chosen adults in Alaska, Idaho, Oregon and Washington in 2002, 2007 and 2012. Return rates in excess of 50\% were received for each survey ensuring that the results were statistically valid. The 2002 survey results were used as base line data. Over $87 \%$ of the respondents undertook at least one voluntary action to protect the quantity of water resources based on the 2012 survey. Voluntary actions including installation of water saving appliances, changing water use in the yard, changing household water use and changing the way a vehicle was washed were taken by $70.2 \%, 49.2 \%, 64.3 \%$ and $32.1 \%$ of the survey respondents, respectively. Voluntary actions taken to protect water quality also improved in 2012 compared with the results of the 2002 and 2007 surveys. The percentage of respondents that improved home waste disposal practices improved their use of pesticides and/or fertilizers in their yards, and safely disposed of used motor oil in 2012 was $60.2 \%, 46.4 \%$ and $65.3 \%$, respectively. Less than $14 \%$ and $19 \%$ of adults have not voluntarily addressed water quantity and water quality issues in their homes, respectively. Any activity that protects the integrity of water resources improves sustainability. The surveys conducted over a 10-year period show increasing citizen participation in efforts to protect water resources. Consequently, it appears that public education targeted at adults does work. Continued public education efforts targeted at adults over the next decade should continue to further increase public participation and the number of best management practices each citizen employs to protect their water resources. Compared with a traditional regulatory approach, the cost of public education to encourage the conservation and protection of water resources is a bargain. Consequently, the USA's land grant universities and other governmental and non-government organizations that invest in adult education should continue to do so. From a taxpayer standpoint, this investment in water education is an efficient and wise use of money.

Keywords: positive life-style change, public actions, public opinion, voluntary actions, water quality, water quantity, water sustainability.
\end{abstract}

\section{INTRODUCTION}

Planet Earth's fresh water supply is finite and small compared with the total amount of water within the hydrologic cycle. Humans are highly dependent on this water supply for drinking, agricultural, energy, ecosystem and recreational purposes to name just a few. However, human population growth, increasing affluence, life style changes and climate change have all contributed to the increased demand for fresh water and increased scarcity $[1,2]$. The protection of planet Earth's water resources has been a paramount environmental issue in the scientific community for over 50 years.

The Earth is currently feeding more than 7,000,000,000 people. This has been possible largely through scientific advances in agriculture and the use of the fresh water resource through precipitation and using irrigation in arid regions. The world's two most populous countries, China and India, are highly dependent on irrigation through the use of surface and ground water to grow enough food for their large populations [3]. Both countries are currently self-sufficient in food production; however, this has come at the expense of reduced river flows and declining ground water tables. Due to 
the high demand for irrigation water in parts of these two countries, water tables have fallen by more than $20 \mathrm{~m}$ per decade. At some point, unless carefully managed, these water resources will become exhausted and as a consequence less food will be produced [4].

China, the world's most populous country, has serious water resource issues. Some of these issues include: (1) over two-thirds of cities have water shortages, (2) over $40 \%$ of the rivers are severely polluted, (3) over $80 \%$ of the lakes suffer from eutrophication, (4) over 300,000,000 people lack access to safe drinking water, (5) eutrophication has become a major issue along popular coastal beaches and (6) severely declining water tables $[4,5]$.

China currently has a per capita renewable fresh water availability amount that is only $25 \%$ of the world average; however, water consumption per unit of domestic gross product is over three times the world average [6]. This intensiveness of per capita water use is due to: (1) the water intensive industrial structure, (2) outdated water delivery technologies, (3) a low rate of water re-use, (4) wastefulness and (5) irrigation inefficiency. The water resource situation in India, the second most populous country in the world, is similarly serious. The only reason China and India are currently feeding their 2,000,000,000 people is because they are mining their ground water resources. At some point, the diminishing ground water supply will cause a reduction in food production. Other drier areas of the world including North Africa, the Middle East, the Aral Sea region and the western USA face similar situations [4].

Many municipal governments have tried to reduce water use through the use of education and/or incentives. In Miami-Dade County, Florida, household water demand was reduced by an average of $200 \mathrm{~L}$ per day [7]. This was equivalent to a $31 \%$ reduction in household water use. Education efforts to build capacity and awareness have also been successful at conserving water use in parts of Australia $[8]$ and other parts of the USA $[9,10]$.

There is an important link between the quality and quantity of water resources. Declines in ground water often have negative effects on both the quality and quantity of surface waters. In parts of northern China irrigation water returns are the major recharge sources for declining aquifers [4]. Unfortunately, this surface water (return irrigation water) is of poor quality and this in turn negatively affects ground water quality. Since over $40 \%$ of the water used in northern China is ground water, concerns about drinking this ground water are significant [11]. Studies have shown that when land use above aquifers changes from agriculture to urban use ground water quality often improves [12]. This observation highlights the damage that agriculture can do to both the quality and quantity of ground water resources.

Sustainability is a term that is often of significant importance when ever water resources are discussed [13]. Although there is general agreement on the definition of sustainability, there are multifaceted threats to achieve actual sustainability. Currently, most scientists agree that sustainable water resources planning must be interdisciplinary. Many water resource managers realize that the assessment of sustainability is incomplete if it does not address economic, environmental and social aspects [14]. In addition, many water resource models address efficiency, equity and sustainability together when trying to optimize water quality and water quantity in a system such as the Rio Grande basin [15]. Several case studies including the Gediz River Basin in Turkey have been based on economic, social and environmental criteria to assess sustainability in water basins [16]. Proposed water resources sustainability indices have made it possible to understand the sustainability of different management options [17].

Due to public pressure to protect surface and groundwater quality and quantity many governments have resorted to a regulatory approach to deal with these complex issues; however, this approach has not always yielded the desired outcomes. Consequently, there has been a groundswell of support for voluntary actions to protect water resources [18]. Several studies have shown that a mixed approach both regulatory and voluntary actions work best [19]. Yet, others have called for the integration of 
voluntary, regulatory and economic strategies to protect both the quality and quantity of water resources [20]. In areas where water quantity is more limiting, a hybrid conservation policy including mandatory restrictions on use, fines for overuse and pricing increases actually could be a more efficient policy rather than a total regulatory or voluntary approach [21]. No matter the type of approach taken to protect water resources success ultimately depends on the involvement of key stakeholder groups at the beginning of the protective effort [22].

Since 1987 in the USA, an increased emphasis has been placed on public education as a mechanism to improve the nation's water resources through voluntary actions. This idea has been implemented by many federal agencies, and through tax dollars money has been linked back to states to get the voluntary process rolling at the local levels. Within the United States Department of Agriculture (USDA), this process was developed and implemented through the National Institute of Food and Agriculture (NIFA) sub agency. USDA-NIFA has placed an emphasis on public education about both water quality and water quantity issues at the local, state, regional and national levels. To discourage states from developing their own water outreach plans since many water issues cross state line boundaries federal dollars were made available on a regional basis. To encourage this regional programming, approximately $\$ 78,000,000$ has been made available on a competitive basis over the last 12 years [23-25].

To accurately determine the effectiveness of regional programming, it is important both to establish base-line information about public perceptions and literacy, and then to measure change in public attitudes and actions over time. Furthermore, to identify the best opportunities for successful regional programming, it is imperative to understand the similarities and differences that exist among the target audiences. In the four-state (Alaska, Idaho, Oregon, Washington) Pacific Northwest (PNW) Region, a survey instrument was developed to provide base-line information on public attitudes regarding water resources in 2002 from which future Extension programming outcomes can be measured [23,25]. This initial regional survey documented public attitudes about water resources in 2002. At that time, it was anticipated that follow-up water resource surveys would be conducted at 5-year (2007), 10-year (2012), 15-year (2017), 20-year (2022) and 25-year (2027)intervals. The first follow-up survey was conducted in 2007 and was used to compare changes in attitudes about water resource issues since 2002 and examine geographic similarities and differences. The second follow-up 5-year survey was completed in 2012. This paper has two objectives: (1) to evaluate the voluntary changes that the public has taken in their lives to address important water quality and quantity issues over the last 10 years and (2) to relate voluntary changes to improved sustainability of water resources in the PNW region of the USA.

\section{METHODOLOGY}

In 2011, a 60-question follow-up survey similar to the surveys conducted in 2002 and 2007 was developed to access public attitudes and actions taken to address water resource issues in the PNW. The specific survey questions discussed in this article deal with actions that the public have voluntarily taken to address both water quality and water quantity issues in the PNW. The survey target audience was a representative sample of the 9,000,000 adult residents of the four PNW states (Alaska, Idaho, Oregon, Washington). In addition, demographic information, including state of residence, community size, length of time residing in the region, gender, age and educational level were also collected from survey respondents.

A target of 950 completed questionnaires was chosen as the survey goal to result in a sampling error of 4-6\% [26]. The survey process was designed to receive a completed survey return rate in excess of 50\%. Addresses were obtained from a professional social sciences survey company (SSI, Norwich, CT). Four mailings were planned to achieve the 50\% return rate [27]. The mailing strategy used was identical to that of the 2002 and 2007 samplings [28-30]. 
Surveys were actually sent to 2,126 residents; however, 240 were returned by the post office as being undeliverable. Consequently, the actual sample population was 1,886 . The survey process was designed to receive a completed survey return rate in excess of 50\%. If more than 943 surveys were returned completed, then sampling error could be assumed to be less than 5\% [26,27].

It only took three mailings to achieve this target return rate of 50\%. The first mailing, which took place in May 2012, included the water issues survey form, a business reply envelope and a cover letter that: (1) identified the survey's authors; (2) explained the purpose of the survey; (3) assured the respondent of anonymity; and (4) asked the respondents to fill out and return the survey via the business reply envelope. The second mailing occurred 5 weeks later (June 2012) and consisted of a postcard that stressed the importance of the survey and remind the respondent to fill out and return the survey sent out in the first mailing. Five weeks later (August 2012), the third mailing was sent to residents who did not respond to the first or second mailing. This mailing included a reminder letter, another copy of the water issues survey and a business reply envelope.

Survey answers were coded and entered into Microsoft Excel. Missing data were excluded from the analysis. The data were analyzed at two levels using SAS [31]. The first level of analysis generated frequencies, whereas the second level evaluated the impacts of demographic factors. Significance $(p<0.05)$ to demographic factors was tested using a chi-square distribution [31].

Each voluntary action to address water quality and water quantity was assigned a sustainability number. These numbers ranged from 1 (low sustainability impact) to 10 (high sustainability impact). These numbers were assigned based on two factors: (1) discussions with educators, water scientists and regulatory officials and (2) using a modification of the index used by Sandoval-Solis et al. [17]. These numbers were then multiplied by the percent of survey respondents that utilized a given practice to determine a net sustainability number. In theory, a net sustainability number could range from 0.0 (no sustainability) to 1.0 (total sustainability). In practice, net sustainability numbers ranged from 0.07 to 0.54 . These net sustainability numbers were then used to compare the importance of voluntarily implemented practices.

The factors used in the sustainability index were based on work by Baan [32] using the following four criteria: (1) socio-economic aspects and impacts on growth, resilience and stability, (2) the use of natural resources including raw materials and discharges, (3) enhancement and conservation of natural and environmental resources with respect to the carrying capacity of the system and (4) public health, safety and well-being. Within these four main criteria, numerical values were developed and assigned for the following sub-criteria: (1) feasibility in socio-economic structure, (2) use of the water resource, (3) waste discharge, (4) water conservation, (5) potential impact on public health, (6) potential impact on safety (risk) and (7) impact on living and working conditions [17,32,33].

\section{RESULTS AND DISCUSSION}

The survey methodology used in the study was not designed to be unique, but rather to be used as a tool to ascertain useful information. The survey methodology was designed to track voluntary implementation of best water management practices, sustainability and to determine additional educational needs. Based on the analysis of collected data, appropriate education programs will be developed for PNW audiences. In addition, the relationship between voluntary actions and sustainability was evaluated.

The 2012 PNW Water Issues Survey achieved a return rate of $54.1 \%$ (1,021 either fully or partially completed and returned out of 1,886). The individual state responses ranged from $49.3 \%$ to $64.5 \%$ (Table 1). Fifty-five percent of the survey respondents were male. Over $38 \%$ of survey respondents lived in communities of more than 100,000 people. Conversely, $16 \%$ of respondents lived in towns with less than 7,000 people. Thirty-nine percent of respondents had lived in the PNW all of their lives. Ninety percent of survey respondents were high school graduates. Overall, the 
demographics of the survey respondents (except for gender) closely reflected the actual demographics of the region. Consequently, when coupled with the low sampling error of the survey, respondents are often equated to residents in the following discussion.

Although the data are not presented in this paper, the 2002, 2007 and 2012 surveys showed that over $90 \%$ of PNW respondents considered clean drinking water, clean rivers and clean groundwater as high priority $[23,25,29,30]$. In addition, over two-thirds of PNW residents indicated that water for power generation, water for agriculture, water for economic development, prevention of the loss of wetlands, prevention of salmon extinction and watershed restoration were high priority. This general information indicates that water issues are considered a high priority by residents of the region.

\subsection{Adult education}

Water resources have always been important to citizens of the USA; however, in the late 1980s several federal and state programs prioritized water as a high priority issue. Regulatory agencies had developed regulatory programs including the Clean Water Act of 1972, the Safe Drinking Water Act of 1974 and the Resource Conservation and Recovery Act of 1976 to protect water resources; however, federal emphasis moved toward voluntary actions to protect water by 1990 . To promote voluntary actions to protect and improve water resources, it was decided that environmental education of school age children and adults needed improvement. Consequently, the Extension branch of land grant universities prioritized water education for adults.

Since 1990, Extension has provided numerous water education opportunities to adults in the PNW. Several of these types of learning opportunities to distribute water information have included the following: (1) development and distribution of printed fact sheets, brochures and/or bulletins; (2) development of user-friendly web sites; (3) workshops and short courses; (4) demonstrations and displays at public events; (5) water information distributed through radio, newspapers and television; (6) videos and DVDs; (7) training for individuals to become volunteers; (8) home, workplace or farm water assessments and (9) opportunities to participate in volunteer activities.

These adult education programs have been successful based on surveys that have shown that over $90 \%$ of adults in the PNW have received educational materials about water resources since 2000. Assessments have also shown that most adults in the region have a high level of comprehension about water issues.

\subsection{Voluntary actions to protect water quality}

Voluntary actions by PNW residents to protect water quality improved in 2012 compared with the results of the 2002 and 2007 surveys (Fig. 1 and Table 2). The percentage of respondents that

Table 1: Pacific Northwest Water Issues Survey sample size and completion rate by state.

\begin{tabular}{lcccc}
\hline State & Population & Sample size & Completed & Return rate (\%) \\
\hline Alaska & 731,000 & 227 & 112 & 49.3 \\
Idaho & $1,595,000$ & 290 & 187 & 64.5 \\
Oregon & $3,899,000$ & 540 & 270 & 50.0 \\
Washington & $6,897,000$ & 829 & 452 & 54.5 \\
Total & $13,122,000$ & 1,886 & 1,021 & 54.1 \\
\hline
\end{tabular}


improved home waste disposal practices, improved their use of pesticides and/or fertilizers in their yards, and safely disposed of used motor oil in 2012 was $60.2 \%, 46.4 \%$ and $65.3 \%$, respectively (Fig. 1). These actions in 2012 were significantly higher than actions in 2002 and 2007 (Table 2). In fact, only $18.6 \%$ of residents reported in the 2012 survey that they did not take at least one voluntary action to protect water quality. This portion of survey respondents that took no action in 2012 is statistically lower than no actions reported in 2007 (26.2\%) and 2002 (45.6\%; Table 2).

Based on the data shown in Fig. 1 and Table 2, the public are getting more involved in the protection of local water quality by taking voluntary actions. Examples of voluntary actions cited by survey respondents to make home waste disposal less harmful to the environment include: (1) eliminating sink disposal of products containing metals, (2) saving products considered hazardous wastes for specific local collection days instead of throwing out with the regular trash, (3) safe disposal of unused pharmaceutical products, (4) composting food wastes when possible, (5) more frequent pump outs of septic tanks, (6) increased recycling and (7) buying more items with minimal packaging.

Examples of voluntary actions the public used with pesticides and fertilizers included: (1) reduced use of pesticides in yards, (2) reduced use of fertilizers in yards, (3) use of slow release fertilizers on lawns, (4) more effective timing of fertilizer applications to match nutrient availability with grass growth, (5) adhering to pesticide application rate labels on products purchased from home and garden centers, (6) making sure that target pests are present on plants prior to pesticide applications and (7) the use of natural pesticides such as soaps that are less harmful to water quality. It is interesting that all of the above practices would be deemed best management practices (BMPs) and have been

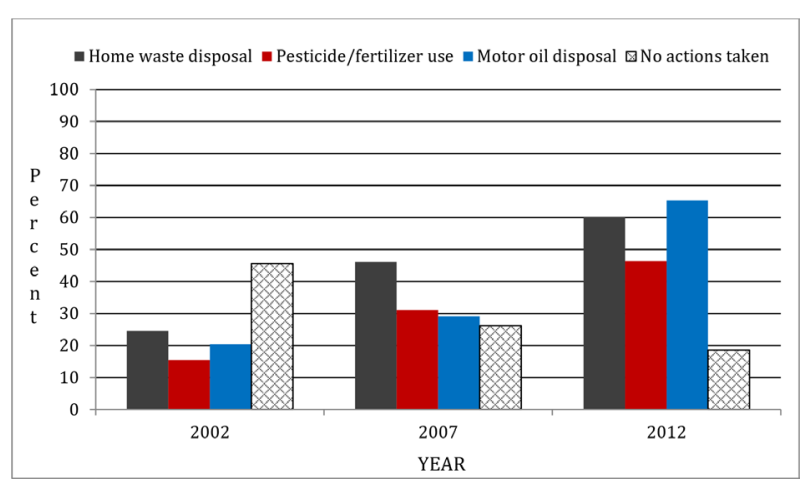

Figure 1: Percentage of survey respondents who have taken a voluntary action to protect water quality based on responses to the 2002, 2007 and 2012 surveys.

Table 2: Statistical significance of time (date) on voluntary actions taken by Pacific Northwest residents comparing 2002 vs. 2012 and 2007 vs. 2012.

\begin{tabular}{lcc}
\hline & 2002 vs. 2012 & 2007 vs. 2012 \\
\cline { 2 - 3 } Action & \multicolumn{2}{c}{$p$-value } \\
\hline Home waste disposal & 0.0001 & 0.0001 \\
Pesticide/fertilizer use & 0.0001 & 0.0001 \\
Motor oil disposal & 0.0001 & 0.0001 \\
No actions taken & 0.0001 & 0.0001 \\
\hline
\end{tabular}


taught through many University outreach programs including the Master Gardeners Program, which is targeted at homeowners.

The rate of motor oil recycling/proper disposal appears to have more than doubled since 2007; however, a large percentage of the public has just probably realized (in the last 5 years) that when they pay for an oil change for their car they also pay an oil disposal fee. It is likely that at least $80 \%$ of the region's residents do not change their own oil. Consequently, the used motor oil has been recycled or safely disposed of by state law for well over a decade. Therefore, even though this recycling is regulated, the consumer has voluntarily made the choice to have their oil changed as a paid service.

The demographic factors of state of residence, occupation, education level and length of residence in the region did not influence the implementation of voluntary actions to protect water quality; however, gender, age and community size did significantly affect the use of voluntary activities. Although the data are not shown in tabular form gender was statistically significant. Females were more likely than males to voluntarily protect water quality through better home waste disposal methods $(68.4 \%$ vs. $54.1 \%)$, more effective fertilizer/pesticide use $(52.8 \%$ vs. $41.7 \%)$ and correctly disposing of used motor oil ( $77.4 \%$ vs. $51.9 \%)$. Males were significantly more likely to not have taken actions to protect water quality ( $22.4 \%$ vs. $14.2 \%)$.

Respondent age had a significant effect on implementing voluntary actions to protect water quality by improving home waste disposal $(p=0.006)$, pesticide/fertilizer use $(p=0.0001)$ and motor oil recycling/disposal ( $p=0.0008$; Fig. 2). It was interesting that respondents in the 30-50 and 50-70 age groups were most likely to implement practices to protect water quality. Respondents over the age of 70 were significantly less likely to consider water quality in their household activities. The under 30 age group did not appear to be as environmentally oriented as their 30-50 and 50-70 age counter parts; however, many wrote individual comments that they did not have to change the way they did things because environmental education in schools had taught them to consider the environment, especially water, in the first place - so they did not need to take corrective actions. Over $80 \%$ of the respondents in the $<30,30-50$ and 50-70 age groups do at least one voluntary action to protect water quality.

Community size also had a significant effect on voluntary actions taken to protect water quality (Fig. 3). In general, respondents living in larger communities were more likely to use water quality friendly tactics when considering home waste disposal $(p=0.0001)$, pesticide/fertilizer use $(p=0.0001)$ and motor oil disposal/recycling $(p=0.0001)$. People living in larger cities and towns generally have smaller residential lots and consequently less space to dispose of wastes. In addition, urban centers in the PNW are known for their recycling and green ethics. Both ethics probably

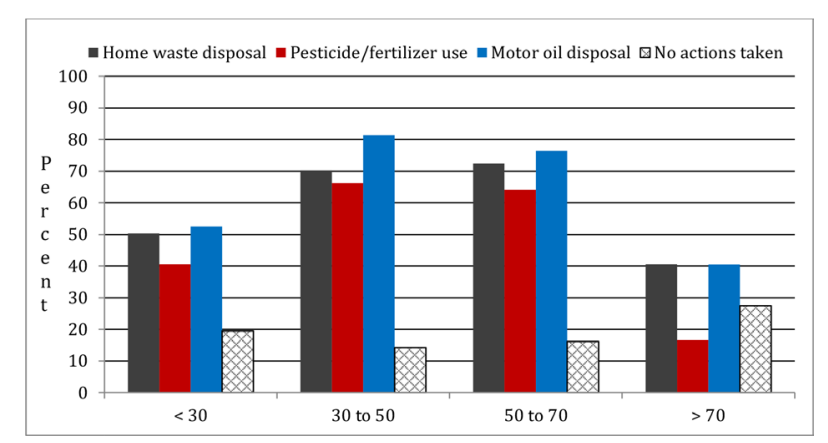

Figure 2: Interaction of respondent age on voluntary actions taken to protect water quality based on responses to the 2012 survey. 


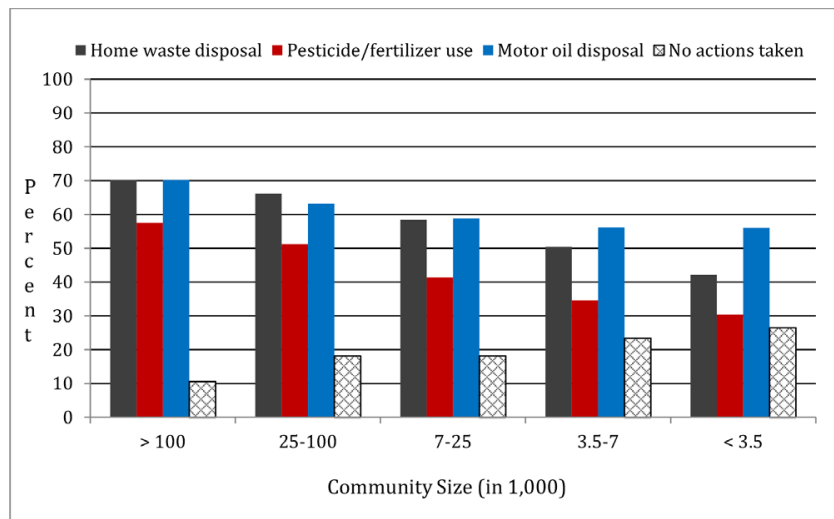

Figure 3: Interaction of the community size of the respondent on voluntary actions taken to protect water quality based on responses to the 2012 survey.

translate into more concern and activism for the environment. It is also interesting to note that less than $11 \%$ of residents in towns of more than 100,000 people took no voluntary actions to protect water quality while this number was over $26 \%$ in towns of less than 3,500 people.

\subsection{Voluntary actions to protect water quantity}

Over $87 \%$ of survey respondents undertook at least one voluntary action to protect the quantity of water resources in the PNW based on the 2012 survey. Voluntary actions including installation of water saving appliances, changing water use in the yard, changing household water use and changing the way a vehicle was washed were taken by $70.2 \%, 49.2 \%, 64.3 \%$ and $32.1 \%$ of the survey respondents, respectively (Table 3 ). All actions were statistically more frequent when compared with the 2002 survey (Table 4). The 2012 results for installing a water-saving appliance and changing household water use were statistically more frequent than the 2007 survey results (Table 4).

Respondent cited examples of installing water saving appliances included: (1) low flush toilets, (2) low flow shower heads, (3) fixing faucet leaks, (4) buying water efficient washing machines, (5) buying water efficient dishwashers and (6) installing ice makers in freezers.

Table 3: Percentage of survey respondents who have taken a voluntary action to protect water quantity based on responses to the 2002, 2007 and 2012 surveys.

\begin{tabular}{lccc}
\hline & 2002 & 2007 & 2012 \\
\cline { 2 - 4 } Action & & $\%$ & \\
\hline Installed water saving appliance & 40.6 & 58.8 & 70.2 \\
Changed yard watering & 28.9 & 46.0 & 49.2 \\
Changed household water use & 32.4 & 42.9 & 64.3 \\
Changed vehicle washing & 26.7 & 30.0 & 32.1 \\
No actions taken & 28.9 & 17.5 & 12.4 \\
\hline
\end{tabular}


Table 4: Statistical significance of time (date) on voluntary actions to protect water quantity taken by Pacific Northwest residents comparing 2002 vs. 2012 and 2007 vs. 2012.

\begin{tabular}{lcc}
\hline & 2002 vs. 2012 & 2007 vs. 2012 \\
\cline { 2 - 3 } Action & \multicolumn{2}{c}{$p$-value } \\
\hline Installed water saving appliance & 0.0001 & 0.0008 \\
Changed yard watering & 0.0001 & $0.072(\mathrm{NS})$ \\
Changed household water use & 0.0001 & 0.0001 \\
Changed vehicle washing & 0.0140 & $0.085(\mathrm{NS})$ \\
No actions taken & 0.0001 & 0.042 \\
\hline
\end{tabular}

Table 5: Interaction of respondent age on voluntary actions taken to protect water quantity based on responses to the 2012 survey.

\begin{tabular}{lcccc}
\hline & \multicolumn{5}{c}{ Age } \\
\cline { 2 - 5 } & $<40$ & $40-50$ & $50-70$ & $>70$ \\
\cline { 2 - 5 } Action & \multicolumn{4}{c}{$\%$} \\
\hline Water saving appliance & 60.3 & 80.1 & 78.6 & 50.1 \\
Changed yard watering & 39.4 & 62.4 & 52.5 & 38.6 \\
Changed household water use & 59.4 & 70.1 & 64.0 & 54.4 \\
No actions taken & 9.4 & 8.4 & 10.2 & 16.9 \\
\hline
\end{tabular}

Changing yard watering strategies cited by survey respondents included: (1) watering lawns less frequently, (2) installing sprinklers, (3) installing timers on sprinkler systems, (4) watering large plants with drip irrigation, (5) using xeriscaping more often, (6) using more native plants in the landscape, (7) using grass varieties that are more tolerant of dry conditions, (8) removing portions of the lawn and (9) replacing lawns with artificial turf.

Survey respondents indicated that they reduced home water use by doing at least one of the following: (1) taking shorter showers, (2) installing low flow shower heads, (3) using low flush toilets, (4) only wash full loads of laundry, (5) only wash full loads in the dishwasher and (6) reduce water flowing out of the faucet when doing simple things like brushing teeth, shaving or washing vegetables.

Getting over $60 \%$ of the public to voluntarily install a water saving device and change household water use indicated that public education about the need for wisely using water resources has been successful. Change in yard water use between 2007 and 2012 was not significant perhaps due to two factors. First, people who had control of watering yards had already made the change by 2007 $(46.0 \%)$ and secondly, renters and apartment dwellers may not have been in the position to impact yard watering. The lack of change in car washing between 2007 and 2012 may also be due to the observation that people who could make changes had already done this by $2007(30.0 \%)$. In addition, many people take their cars to pay wash stations rather than wash vehicles at home. It appears that public education has made PNW residents willing to try to do the right thing by taking voluntary actions to protect their water quantity resources. 
Table 6: Interaction of respondent state of residence on voluntary actions taken to protect water quantity based on responses to the 2012 survey.

\begin{tabular}{lrrrr}
\hline & \multicolumn{4}{c}{ State } \\
\cline { 2 - 5 } & AK & ID & OR & WA \\
\cline { 2 - 5 } Action & \multicolumn{4}{c}{$\%$} \\
\hline Water saving appliance & 49.6 & 63.2 & 76.7 & 75.4 \\
Changed yard watering & 30.6 & 56.4 & 49.6 & 51.1 \\
Changed household water use & 55.8 & 67.3 & 64.1 & 65.4 \\
No actions taken & 20.4 & 9.4 & 9.0 & 9.6 \\
\hline
\end{tabular}

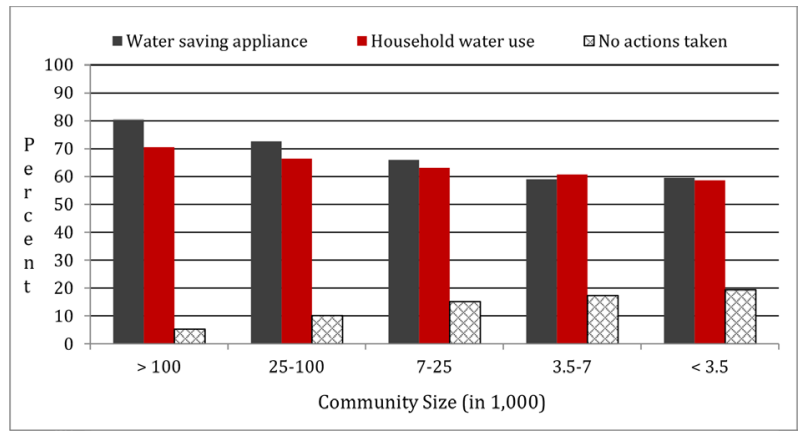

Figure 4: Interaction of the community size of the respondent on voluntary actions taken to protect water quantity based on responses to the 2012 survey.

The demographic factors of education and length of time living in the PNW did not affect voluntary actions to reduce water use by survey respondents; however, gender, community size, age and state of residence did impact actions to protect water quantity (Tables 5 and 6 and Fig. 4).

Although not shown in tabular form, based on the 2012 survey females were more likely than males to have installed a water saving appliance $(76.2 \%$ vs. $65.1 \% ; p=0.02)$, changed watering in the yard $(57.8 \%$ vs. $41.4 \% ; p=0.004)$, changed household water use $(67.6 \%$ vs. $60.5 \% ; p=0.03)$ and changed how a vehicle was washed $(37.9 \%$ vs. $26.4 \% ; p=0.026)$. Gender produced similar significant statistical trends for both water quality and water quantity actions assessed in the survey.

Respondent age had a significant impact on the voluntary actions of installing a water saving appliance $(p=0.004)$, changing water use in the yard $(p=0.0006)$ and changing household water use $(p=0.008)$ in the 2012 survey (Table 5). Age did not impact voluntary actions to change the way a vehicle was washed. Less than $11 \%$ of the survey respondents in the less than 40, 40-50 and 50-70 age groups took no actions to voluntarily protect water (quantity) resources (Table 5). However, a much higher $16.9 \%$ of respondents older than 70 did not take one or more proactive water quantity actions $(p=0.0001)$.

State of residence impacted answers to installing a water saving appliance $(p=0.003)$, changing water use in the yard $(p=0.004)$ and changing household water use $(p=0.03)$ (Table 6). The responses from Alaska were the most likely reason for the observed significant differences. Alaska 
residents were less likely to voluntarily take the three significant actions compared with residents of Idaho, Oregon and Washington. Oregon and Washington residents responded similarly to all three actions. Idaho residents were less likely to install water savings appliances but more likely to change yard watering compared with Oregon and Washington.

Differences between states can likely be related to climatic factors. First, there is very little perception of water shortages in larger sized cities and towns in Alaska. Second, the highly populated areas of Washington and Oregon receive adequate annual precipitation to meet most needs; however, the high and rapidly increasing population tends to offset the water surplus. Third, Idaho is the driest state and thus the tendencies for changes in yard and household water use are apparent. Over $90 \%$ of Idaho, Oregon and Washington survey respondents have taken at least one action to protect water (quantity) resources, while one in five Alaska residents have taken no actions ( $p=0.0001$; Table 6).

Community size significantly impacted the rate of voluntary actions to install water saving appliances $(p=0.024)$ and change household water use ( $p=0.013$; Fig. 4$)$. Community size did not impact change in yard water use and change in washing a vehicle. In general, respondents living in larger cities and towns were more likely to have installed a water savings appliance than counterparts in smaller communities (Fig. 4). The same significant trend is also seen for changes in household water use. Community size affected answers to both water quality and water quantity actions in a similar manner. Over $94 \%$ of survey respondents in communities with more than 100,000 took at least one voluntary action to address water (quantity) resources. In contrast, almost $20 \%$ of respondents in communities with less than 7,000 people took no actions to address the same issues.

\subsection{Water quality sustainability}

Voluntary practices used to correctly dispose of household wastes received a sustainability rating of 9 . When multiplied by the percentage of survey respondents who implemented one or more of the BMPs a net sustainability score of 0.54 was assigned (Table 7). Safe disposal of household wastes including hazardous wastes, unwanted pharmaceutical products, food wastes, solids from septic systems and the increased use of recycling improved the sustainability of water resources. Surface waters, either directly or indirectly, often receives the majority of these waste products. Consequently, the sustainability of surface water quality is particularly enhanced.

Changes in fertilizer/pesticide use received a sustainability rating of 6 . When multiplied by the $46 \%$ of survey respondents who had voluntarily used BMPs, a sustainability index of 0.28 was assigned (Table 7). Most of the voluntary practices used by the public targeted either a lower rate of chemical use or using only when strategic to kill a targeted pest. Consequently, less chemicals were

Table 7: Sustainability factor, percentage of survey respondents taking action and net sustainability (NS) for water quality practices implemented voluntarily based on 2012 survey.

\begin{tabular}{lccc}
\hline & Sustainability & Use & NS \\
\cline { 2 - 4 } Action & & $\%$ & \\
\hline Home waste disposal & 9 & 60 & 0.54 \\
Pesticide/fertilizer use & 6 & 46 & 0.28 \\
Motor oil disposal & 2 & 65 & 0.13 \\
\hline
\end{tabular}

NS $=$ sustainability $\times$ use. 
reaching the water supply - which in the long-term would improve the quality of the region's water resources. Unlike with home waste disposal, the improved/reduction usage of fertilizers and pesticides would have more of a positive impact on ground water quality because many of the currently used agrichemicals have a propensity to leach in soils and end up in the ground water.

Motor oil disposal received a lower sustainability value of 2 . When multiplied by the $65 \%$ of survey respondents who used BMPs to deal with motor oil disposal, a sustainability index of 0.13 was assigned (Table 7). The improved disposal of used motor oil takes the pressure off both surface (storm sewers) and ground water (leaching) quality.

All three voluntarily implemented types of practices to improve the sustainability of water quality (disposal of household wastes, reduced fertilizer/pesticide use, proper disposal of motor oil) are now widely used by the public and have a positive impact on water quality. Compared with 2002 because of voluntary public action water quality is more sustainable today in the PNW. This positive impact is starting to be measured in local and regional water sampling studies and it is expected, that in time, the public through voluntary actions have made and will make this resource more sustainable.

\subsection{Water quantity sustainability}

The installation of a water saving appliance received a sustainability rating of 5 . When multiplied by the $70 \%$ of survey respondents who had installed at least one water saving appliance, a sustainability score of 0.35 was assigned (Table 8). The installation of water saving appliances such as low flush toilets, low flow shower heads, water efficient washing machines and/or dishwashers as well as fixing leaky faucets reduced household water use in both large cities like Seattle and in smaller communities including Pullman, Washington and Moscow, Idaho. These water use reductions have been measured in over 30 PNW communities. Reduced household water use through the installation of water saving appliances improves the sustainability of water quantity resources. Both the surface water (Seattle) and ground water (Pullman, Moscow) resources benefit from reduced household water use.

Changes on how a yard is watered received a sustainability number of 7 . When multiplied by the $49 \%$ of survey respondents who changed yard water use a sustainability score of 0.34 was assigned (Table 8). Many residents simply responded to public education by simply watering their lawns less frequently. However, survey respondents who placed a premium on green yards employed strategies including installing sprinklers, which would use less water, installing timers on their irrigation systems, using drip irrigation on large shrubs and plants, and/or using native plants that require less supplemental water. Therefore, basically residents reduced the amount of water traditionally used in

Table 8: Sustainability factor, percentage of survey respondents taking action and net sustainability (NS) for water quantity practices implemented voluntarily based on 2012 survey.

\begin{tabular}{lccc}
\hline & Sustainability & Use & NS \\
\cline { 2 - 4 } Action & \multicolumn{3}{c}{$\%$} \\
\hline Installed water saving appliance & 5 & 70 & 0.35 \\
Changed yard watering & 7 & 49 & 0.34 \\
Changed household water use & 4 & 64 & 0.26 \\
Changed vehicle washing & 1 & 65 & 0.07 \\
\hline
\end{tabular}

NS $=$ sustainability $\times$ use. 
their yards. In the long term, this strategy will reduce the quantity of water withdrawals from ground and surface waters in the region - thus making water resources more sustainable. The reduction in yard water use was greater in the drier areas of the four-state region. Thus, the areas with the fewest water resources benefited disproportionately with water savings.

A net sustainability value of 0.26 was assigned for the change in household water use based on a sustainability value of $4 \%$ and $64 \%$ of survey respondents using these practices (Table 8 ). Due to public education, a majority of PNW adults used one or more of the following to reduce household water use: (1) took shorter showers, (2) installed and used low flush toilets, (3) washed only full loads of laundry and/or dishes and (4) reduced the amount of water free-flowing from faucets. The reduction in household water use corresponds to less demand on the region's water resources. This makes the water system more sustainable in the region.

Voluntary practices used to change how vehicles are washed received a sustainability value of 1 . When multiplied by the $65 \%$ of survey respondents who changes the way they wash a vehicle, a net sustainability value of 0.07 was assigned (Table 8). Adult residents of the PNW use less water to wash their vehicles in 2012 compared with 2002. This reduction in water use helps improve the sustainability of water resources.

The four voluntary practices used to improve the sustainability of water quality in the PNW ranked from most to least sustainable are: (1) installation of a water saving appliance, (2) changes in yard watering, (3) changes in household water use and (4) changes in washing vehicles. All four water saving practices are important because over $48 \%$ of the adult public voluntarily used at least one of these practices to protect their water resources. Compared with 2002 and 2007 survey results, water resources are more sustainable today in the PNW.

\section{CONCLUSIONS AND RECOMMENDATIONS}

Voluntary actions taken by adults in the PNW are linked to the protection of the region's water resources. Any positive action that an individual citizen undertakes to protect water quality and/or water quantity improves the sustainability of the water resource. Consequently, when 7,200,000 citizens, about $80 \%$ of the region's adults based on the 2012 survey, take positive actions the sustainability of the water resource is significantly enhanced.

The surveys conducted over a 10-year period show increasing citizen participation in efforts to protect water resources. Consequently, it appears that public education targeted at adults does work. Continued public education efforts targeted at adults over the next decade should continue to further increase public participation and the number of BMPs each citizen employs to protect their water resources.

Compared with a traditional regulatory approach, the cost of public education to encourage the conservation and protection of water resources is a bargain. Consequently, the USA's land grant universities and other governmental and NGOs that invest in adult education should continue to do so. From a taxpayer standpoint, this investment in water education is an efficient and wise use of money.

Adult education about water issues in the PNW has been deemed successful because the public is aware of the important water issues in the region. More importantly, many citizens have taken additional steps including taking voluntary actions to protect their water resources through individual pollution prevention and/or water conservation activities. Knowledge is power. Based on this PNW, experience education can empower citizens to take positive actions about their water resources. There is every reason to believe that educational programs that translate into voluntary actions can be successful in both developed and developing countries. Although the level of educational technologies employed to provide water education to adults may be less in large developing countries like China, India, Indonesia, Nigeria and Bangladesh, the authors believe that this technique employing strategies to educate adults about water resources can improve water resources on a world-wide basis. 


\section{ACKNOWLEDGEMENTS}

The authors acknowledge two projects funded by the USDA National Institute of Food and Agriculture. The first project is Coordination of Water Resources in the Pacific Northwest (contract numbers \#2000-5495 and \#2004-51130-02245). The second project is Regional Approaches to Climate Change for Pacific Nortwest Agriculture (REACCH) (contract number \#2011-68002-30191).

\section{REFERENCES}

[1] Arnell, N.W., van Vuuren, D.P. \& Isaac, M.The implications of climate policy for the impacts of climate change on global water resources. Global Environmental Change, 21, pp. 592-603, 2011. doi: http://dx.doi.org/10.1016/j.gloenvcha.2011.01.015

[2] Postel, S.L., Daily, G.C. \& Ehrlich, P.R. Human appropriation of renewable fresh water. Science, 271, pp. 785-788, 1996. doi: http://dx.doi.org/10.1126/science.271.5250.785

[3] Brown, L.R.. Eradicating hunger: a growing challenge. State of the World 2001, eds L.R. Brown,C. Flavin, H. French, Norton \& Company: New York, pp. 43-62.

[4] Currell, M.J., Han, D., Chen, Z. \& Cartwright, I., Sustainability of ground water usage in northern China: dependence on paleowaters and effects on water quality, quantity and ecosystem health. Hydrologic Processes, 26, pp. 4050-4066, 2012. doi: http://dx.doi.org/10.1002/ hyp. 9208

[5] Liu, J. \& Yang, W., Water sustainability for China and beyond. Science, 337(6095), pp. 649-650, 2012. DOI: 10.1126/science 1219471; available at: hhtp://www.sciencemag.org/content/337/6095/649.full.

[6] Chinese Academy of Sciences, China Sustainable Development Strategy Report 2007 - Water: Governance and Innovation, Science Press: Beijing, 2007.

[7] Lee, M., Tansel, B. \& Balbin, M., Urban sustainability incentives for residential water conservation: adoption of multiple high efficiency appliances. Water Resources Management, 27, pp. 2531-2540, 2013. doi: http://dx.doi.org/10.1007/s11269-013-0301-8

[8] Turner, A., White, S., Beatty, K. \& Gregory, A., Results of the largest residential demand management program in Australia. Institute for Sustainable Futures, University of Technology, Sydney, 2004.

[9] Willis, R.M., Steward, R.A., Panuwatwanich, K., Jones, S. \& Kyriakides, A., Alarming visual display monitors affecting shower end-use water and energy conservation in Australian residential households. Resources Conservation and Recycling, 54, pp. 1117-1127, 2010. doi: http://dx.doi.org/10.1016/j.resconrec.2010.03.004

[10] Mayer, P.W., Deoreo, W.B., Towler, E. \& Lewis, D.M., Tampa Water Department Residential Water Conservation Study: The Impact of High Efficiency Plumbing Fixture Retrofits in SingleFamily Houses, Aquacraft, Inc.: Tampa, 2004.

[11] OECD, OECD Environmental Performance Review of China. Organization for Economic Co-operation and Development: Paris, 2007, 336 pp, available at: http://1h3ek9yz9r.search. serialssolutions.com/?url_ver=Z39.88_2004\&rft_val_fmt=info\%3Aofi\%2Ffmt\%3Akev\%3A $\mathrm{mtx} \% 3$ Abook\&rft.genre=book

[12] Twarakavi, N.K.C. \& Kaluarachchi, J.J.. Sustainability of ground water quality considering land use changes and public health risks. Journal of Environmental Management, 81, pp. 415-419, 2006. doi: http://dx.doi.org/10.1016/j.jenvman.2005.11.008

[13] Jones, J.A.A., Water Sustainability: A Global Perspective. Hodder Education: London, 452 pp, 2010.

[14] Simonovic, S.P., Measures of sustainability and their utilization in practical water management planning, Regional Management of Water Resources (Proceedings Sixth IAHS Scientific Assembly, Maastricht, the Netherlands). IAHS Publ. no. 268, pp. 3-16. 
[15] Ward, F.A. \& Pulido-Velazquez, M, Efficiency, equity and sustainability in a water quantityquality optimization model in the Rio Grande basin. Ecological Economics, 66, pp. 23-37, 2008. doi: http://dx.doi.org/10.1016/j.ecolecon.2007.08.018

[16] Harmancioglu, N.B., Barbaros, F. \& Centinkaya, C.P., Sustainability issues in water management. Water Resources Management, 27, pp. 1867-1891, 2013. doi: http://dx.doi.org/10.1007/ s11269-012-0172-4

[17] Sandoval-Solis, S. \& McKinney, L.D.P., Sustainability index for water resources planning and management. Journal of Water Resources Planning and Management, 137, pp. 381-390, 2011. doi: 10.1061/(ASCE)WR.1943-5452.0000134.

[18] Anonymous, Voluntary action needed to protect water quality. Journal of Environmental Health, 53(2) 6 pp, 1990.

[19] May, P.J., Marine facilities and water quality: regulatory versus voluntary approaches. Coastal Management, 31, pp. 297-317, 2003. doi: http://dx.doi.org/10.1080/08920750390233009

[20] Neufield, D.A., An ecosystem approach for groundwater: the case of Waterloo Region, Ontario, Canada. Hydrogeology Journal, 8, pp. 239-250, 2000. doi: http://dx.doi.org/10.1007/p100021536

[21] Pumphrey, R.G., Edwards, J.A. \& Becker, K.G., Urban and rural attitudes toward municipal water controls: a study of a semi-arid region with limited water supplies. Ecological Economics, 65, pp. 1-12, 2008.

[22] Koski, C. \& May, P.J., Interest and implementation: fostering voluntary regulatory actions. Journal of Public Administration Research and Theory, 16, pp. 329-349, 2006. doi: http:// dx.doi.org/10.1093/jopart/mui048

[23] Mahler, R.L., Simmons, R. \& Simmons, F., Public perceptions and actions toward sustainable groundwater management in the Pacific Northwest region, USA. International Journal of Water Resources Development, 21, pp. 465-472, 2005. doi: http://dx.doi. org/10.1080/07900620500036604

[24] Shepard, R., Evaluating extension-based water resource outreach programs: are we meeting the challenge? Journal of Extension, 40(1), 2002, available at http://www.joe.org/ joe/2002february/a3.html [On-line].

[25] Mahler, R.L., Simmons, R., Sorensen, F. \& Miner, J.R., Priority water issues in the Pacific Northwest. Journal of Extension, 42(5), Article 5RIB3, 2004. Available at http://www.joe.org/ joe/2004october/rb3.php [On-line].

[26] Salent, P. \& Dillman, D., How to Conduct Your Own Survey, John Wiley and Sons, Inc.: New York, New York, 1994.

[27] Dillman, D., Mail and Internet Surveys: The Tailored Design Method, John Wiley and Sons, Inc.: New York, New York, 2000.

[28] Mahler, R.L., Gamroth, M., Pearson, P., Sorenson, F., Barber, M.E. \& Simmons, R., Information sources, learning opportunities and priority water issues in the Pacific Northwest. Journal of Extension, 48(2), Article 2RIB2, 2010, available at http://www.joe.org/joe/2010april/rb2.php [On-line].

[29] SAS Institute, Inc., SAS Online Document 9.1.3, SAS Institute, Inc.: Cary, NC, 2004.

[30] Mahler, R.L. \& Barber, M.E., Public actions taken to address water quality and quantity issues in the northwestern USA since pp. 263-274, 2002. WIT Transactions on Ecosystems and Sustainable Development IX, 175, 2013, ISSN 1743-3541, doi: 10.2495/ECOI 130221.

[31] Babbie, E., The Practice of Social Research, 3rd edn, Wadsworth Publishing Company: Belmont, CA, pp. 359, 424, 1983.

[32] Baan, J.A., Evaluation of water resource projects on sustainable development. Proc. Int. UNESCO Symposium Water Resources Planning in a Changing World, Karlsruhe, Germany, 28-30 June, IV, pp. 63-72, 1994.

[33] Loucks, D.P., Quantifying trends in system sustainability. Hydrological Sciences Journal, 42(4), pp. 513-530, 1997. doi: 10.1080/02626669709492051. 